\title{
Critical analysis of adsorption data statistically
}

\author{
Achla Kaushal $^{1}$ (D) S. K. Singh ${ }^{2}$
}

Received: 2 May 2016/Accepted: 31 August 2016/Published online: 26 September 2016

(c) The Author(s) 2016. This article is published with open access at Springerlink.com

\begin{abstract}
Experimental data can be presented, computed, and critically analysed in a different way using statistics. A variety of statistical tests are used to make decisions about the significance and validity of the experimental data. In the present study, adsorption was carried out to remove zinc ions from contaminated aqueous solution using mango leaf powder. The experimental data was analysed statistically by hypothesis testing applying $t$ test, paired $t$ test and Chi-square test to (a) test the optimum value of the process $\mathrm{pH}$, (b) verify the success of experiment and (c) study the effect of adsorbent dose in zinc ion removal from aqueous solutions. Comparison of calculated and tabulated values of $t$ and $\chi^{2}$ showed the results in favour of the data collected from the experiment and this has been shown on probability charts. $K$ value for Langmuir isotherm was 0.8582 and $m$ value for Freundlich adsorption isotherm obtained was 0.725 , both are $<1$, indicating favourable isotherms. Karl Pearson's correlation coefficient values for Langmuir and Freundlich adsorption isotherms were obtained as 0.99 and 0.95 respectively, which show higher degree of correlation between the variables. This validates the data obtained for adsorption of zinc ions from the contaminated aqueous solution with the help of mango leaf powder.
\end{abstract}

Achla Kaushal

achla001@hotmail.com

S. K. Singh

sksinghdce@gmail.com

1 Faculty, Department of Chemical Engineering, Guru Nanak Dev Institute of Technology, Delhi, India

2 Department of Environmental Engineering, Delhi Technological University, Delhi, India
Keywords Adsorption - Hypothesis testing - Karl Pearson's correlation coefficient · Probability charts . Statistical analysis

\section{Introduction}

Although adsorption is a common phenomenon for gas phase, yet it is widely used in the treatment of waste water. It has been used in purification and disinfection of potable water since ancient times by Romans, Egyptians and Sumerians (Dabrowski 2001; Ferhan and Ozgur 2011). For past couple of decades, increased urbanisation and industrialisation has resulted in high concentration of heavy metal ions in water bodies and drinking water supplies, which are harmful for life. Heavy metals are toxic, persistent and are mostly non-biodegradable. They pose a serious threat to life when consumed in quantities higher than the prescribed values. Their presence above prescribed limits can cause severe damages to vital organs of the body, such as kidney, liver and brain, reproductive and nervous system (Goel 2006).

Adsorption using low cost agricultural waste as an adsorbent is one of the known methods in waste water treatment for its significant metal removal efficiency and availability of a wide range of adsorbents. A number of adsorbents prepared from (a) agricultural waste such as rice husk, coconut coir, onion skin, (b) tree leaves such as peepal, neem, and mango, (c) chemically modified waste, such as cassava starch, modified potato and onion peals, and (d) activated carbon from coconut shell, apricot stone, etc. have been studied to remove heavy metal ions from waste water solutions (Wong et al. 2003; Conrad and Hansen 2007; Cafer et al. 2012; Sharma et al. 2014; Tiwari et al. 2014; Shah et al. 2015; Singh and Narwal 2015; 


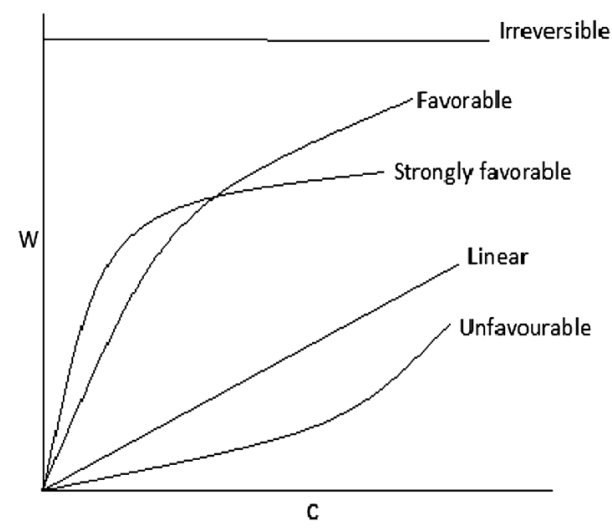

Fig. 1 Arithmetic graph between metal ion concentration $c(\mathrm{mg} / \mathrm{L})$ vs adsorbent loading $W$ (g adsorbed/g solid) presenting different adsorption isotherms

Kaushal and Singh 2016a, b; Raval et al. 2016; Shah et al. 2016). Data obtained from these experiments is studied by adsorption isotherms presented on arithmetic graphs obtained by plotting metal ion concentration $c(\mathrm{mg} / \mathrm{l})$ against adsorbent loading $W$ (g adsorbed/g solid) (Fig. 1).

\section{Karl Pearson's correlation coefficient $(r)$}

Karl Pearson's correlation coefficient is a widely used method to measure the degree of relationship between two variables and is given by

$r=\left[\sum\left(X_{i}-X\right) \cdot\left(Y_{i}-Y\right)\right] / n \cdot \sigma_{x} \cdot \sigma_{Y}$,

where $X$ and $Y$ are the Karl Pearson's correlation coefficient variables. $X_{i}$ and $Y_{i}$ represent $i$ th value of independent variables and $\sigma_{x}$ and $\sigma_{Y}$ represent standard deviations of $X$ and $Y . X$ and $Y$ represent values of $c$ and $c / W$, respectively, for Langmuir isotherm and $c$ and $W$, respectively, for Freundlich adsorption isotherm.

\section{Statistical analysis of experimental data}

To describe the process qualitatively and quantitatively statistically, null hypothesis $\left(H_{\mathrm{o}}\right)$ is defined assuming that it is true. An alternative hypothesis $\left(H_{\mathrm{a}}\right)$ is defined at the same time keeping in view that alternative hypothesis is accepted, if the null hypothesis is rejected or vice-versa. Level of significance, the maximum value of the probability to reject the null hypothesis, is defined before testing the hypothesis (Kaushal and Singh 2016a).

Hypothesis tests, the tests of significance for analysing experimental data are categorised as (1) parametric tests, e.g. Chi-square test, $t$ test, $z$ test and $F$ test (2) non-parametric tests, the distribution-free tests of hypotheses, independent of assumptions based on the characteristics of the original population. $z$ test compares the sample mean with the hypothesised population mean value. It is used to judge the significance of mean for large samples, $n>30$.

$t$ test based on t-distribution is used when population is normal and infinite, population variance is unknown and sample size is small $(n<30)$. It is an appropriate test to judge the significance of difference between two sample means with unknown population variance.

Paired t test compares two related samples for small values of $n$. It is assumed that the two populations are normal. The variance of two populations need not be equal. This test is normally conducted on data before and after treatment studies.

Chi-square $\left(\chi^{2}\right)$ test is a useful statistical technique to test the goodness of fit, significance and independence of population variance. (Bowley 1937; Anderson 1958; Chance 1975; Kothari 1984, 2004).

\section{Adsorption isotherms}

Experimental data is analysed using adsorption isotherm equations (Treybal 1981; McCabe et al. 1993). Isotherm constants are determined and coefficient of correlation is calculated. The linear fit of the experimental data allows to obtain the value of correlation coefficient $>0.90$ (Kothari 2004).

Langmuir isotherm a favourable type of isotherm is given by

$W=W_{\max }(K c /(1+K c)$.

Values of $c$ are plotted against $c / W$ to test the Langmuir isotherm model. Values of Langmuir isotherm constants $K$ and $W_{\max }$ are determined from the plot. If $K$ is large and $K c \gg>1$, the isotherm is strongly favourable. The isotherm is nearly linear when $K c<1$.

Freundlich isotherm also a favourable type of isotherm is given by

$W=b c^{m}$.

$\log c$ is plotted w.r.t. $\log W$ to test the Freundlich isotherm model. Values of Freundlich isotherm constants $b$ and $m$ are determined from the plot. For adsorption from liquids, $m<1$ gives a better fit.

\section{Materials and method}

$10 \mathrm{mg} \mathrm{Zn}$ metal chips (AR) were dissolved in a few drops of conc. HCl. Stock solution was prepared by diluting it to $1 \mathrm{~L}$ with distilled water. This solution was further diluted by adding distilled water to obtain various concentrations in the range $10-100 \mathrm{mg} / \mathrm{L}$. Mango tree leaves collected from local area were washed, dried and crushed to 200 
mesh size. They were washed repeatedly to get rid off the colour and other impurities, dried for $6 \mathrm{~h}$ at $60{ }^{\circ} \mathrm{C}$ in a hot air oven and stored in air tight container. This dried powder used in the range $1-10 \mathrm{~g} / \mathrm{L}$ was used to calculate the $\%$ removal of $\mathrm{Zn}$ ions from the solution. Batch experiment was carried out in the 'Orbital' constant temperature variable speed shaker holding 12 Erlenmeyer flasks at a time at $20{ }^{\circ} \mathrm{C}$ and $150 \mathrm{rpm}$ for $100 \mathrm{~min}$ in the $\mathrm{pH}$ range $2-8$. The solutions were filtered with Whatman filter paper no. 40 after each batch experiment. Analysis of concentration of zinc ions in the filtrate was done by CHEMITO AA201 Atomic Absorption Spectrophotometer (AAS) using airacetylene flame. Percentage removal of zinc ions from the solution after the batch adsorption was calculated as

$\%$ Removal $=\left[\left(C_{\mathrm{i}}-C_{\mathrm{o}}\right) / C_{\mathrm{i}}\right] \times 100$,

where $C_{\mathrm{o}}$ and $C_{\mathrm{i}}$ represent the final and initial concentration zinc ions $(\mathrm{mg} / \mathrm{L})$ in the solution, respectively.

$q_{\mathrm{e}}=\left[\left(C_{\mathrm{i}}-C_{\mathrm{e}}\right) V\right] / m$,

where $q_{\mathrm{e}}$ is the equilibrium adsorption capacity (mg adsorbate/g adsorbent) and $V$ is the volume of the solution (litres) and $m$ is the mass of the adsorbent ( $g$ ) used (Kaushal and Singh 2016b).

\section{Results and discussion}

Data collected from analysis of the filtrates for zinc ion concentration was used for

(A) Testing the hypotheses: (1) to judge the optimum value of $\mathrm{pH}$ for maximum zinc ion removal from solution (2) to judge the success of the experiment (3) to infer that the higher adsorbent dose helps in higher \% removal of zinc ions (4) to judge the $K$ value for favorability of Langmuir isotherm (5) to judge the $\mathrm{m}$ value for favourability of Freundlich isotherm

(B) To test the fitness of data in Langmuir and Freundlich adsorption isotherms using Karl Pearson's correlation coefficient given by $r=\sum\left(X_{\mathrm{i}}-X\right) \cdot\left(Y_{\mathrm{i}}-Y\right) / n \cdot \sigma_{x} \cdot \sigma_{y}($ Eq. 1$)$

\section{Hypothesis testing to judge the optimum value of $\mathrm{pH}$ for maximum removal of the zinc ions from the solution containing $100 \mathrm{ppm}$ zinc ion concentration}

Two-tailed $t$ test was applied to judge the optimum value of $\mathrm{pH}$ within $5 \%$ level of significance (Table 1).

Null hypothesis $H_{\mathrm{o}}: \mu_{H_{\mathrm{o}}}=$ Optimum $\mathrm{pH}=5$

Alternate hypothesis $H_{\mathrm{a}}$ : Optimum $\mathrm{pH} \neq 5$.
Table $1 \%$ removal of zinc ions w.r.t. $\mathrm{pH}$

\begin{tabular}{llcc}
\hline$n$ & $\mathrm{pH}$ & \% Removal $\left(\mathrm{X}_{\mathrm{i}}\right)$ & $\left(X_{\mathrm{i}}-X_{\text {avg }}\right)^{2}$ \\
\hline 1 & 2 & 30 & 866.04 \\
2 & 3 & 42 & 303.76 \\
3 & 4 & 70 & 111.76 \\
4 & 5 & 75 & 242.47 \\
5 & 6 & 73 & 184.18 \\
6 & 7 & 67 & 57.33 \\
7 & 8 & 59 & 0.18 \\
Sum $\sum X_{\mathrm{i}}$ & & 416 & \\
Avg X & & 59.43 & \\
\hline
\end{tabular}

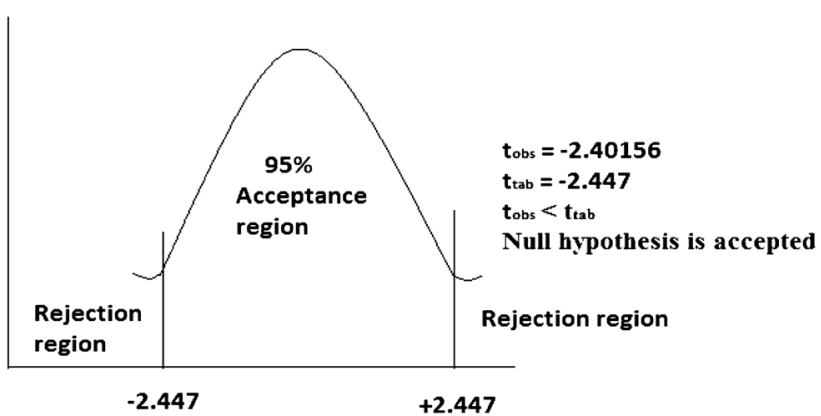

Fig. 2 Probability chart for $t$-distribution for two-tailed test

For $(n-1)$ degree of freedoms

$\left.t=\left(\mathrm{X}_{\mathrm{avg}}-\mu\right)\right) /\left(\sigma_{\mathrm{s}} / \sqrt{ } n\right)=t_{\text {observed }}$,

is the calculated value of $t$,

where $\sigma_{\mathrm{s}}=$ standard deviation $=\sqrt{ }\left[\sum\left(X_{\mathrm{i}}-X_{\mathrm{avg}}\right)^{2} /\right.$ $(n-1)]$,

$\mathrm{X}_{\mathrm{avg}}=$ Average value of $X$ and $n=$ sample size.

From Eq. 6, the value of standard deviation $\sigma_{\mathrm{s}}=17.15$ and calculated value of $t, t_{\text {observed }}=-2.40156$, whereas $t_{\text {tabulated }}=-2.447$ at $5 \%$ level of significance for 6 degrees of freedom (d.f.) for 2-tailed $t$-distribution (Kothari 2004). Since $t_{\text {observed }}<t_{\text {tabulated, null hypothesis that the }}$ optimum value of $\mathrm{pH}$ is 5 is accepted (Fig. 2).

\section{Hypothesis testing to judge the success of the experiment}

Paired $t$ test was applied on the matched pairs, i.e. the concentration values of zinc ion in the solution before $\left(X_{\mathrm{i}}\right)$ and after $\left(Y_{\mathrm{i}}\right)$ the adsorption experiment (Table 2).

Null hypothesis $H_{\mathrm{o}}$ : Experiment did not bring any change in the concentration of zinc ions in the solution.

Alternate hypothesis $H_{\mathrm{a}}$ : Adsorption experiment was successful. 
Table 2 Zinc ion concentration in the solution before $\left(X_{\mathrm{i}}\right)$ and after $\left(Y_{\mathrm{i}}\right)$ the experiment

\begin{tabular}{lccc}
\hline$n$ & $X_{\mathrm{i}}$ & $Y_{\mathrm{i}}$ & $D_{\mathrm{i}}=X_{\mathrm{i}}-Y_{\mathrm{i}}$ \\
\hline 1 & 10 & 2.5 & 7.5 \\
2 & 20 & 5 & 15 \\
3 & 30 & 9 & 21 \\
4 & 40 & 14 & 26 \\
5 & 50 & 20 & 30 \\
6 & 60 & 26 & 34 \\
7 & 70 & 32 & 38 \\
8 & 80 & 39 & 41 \\
9 & 90 & 47 & 43 \\
10 & 100 & 56 & 44 \\
\hline
\end{tabular}

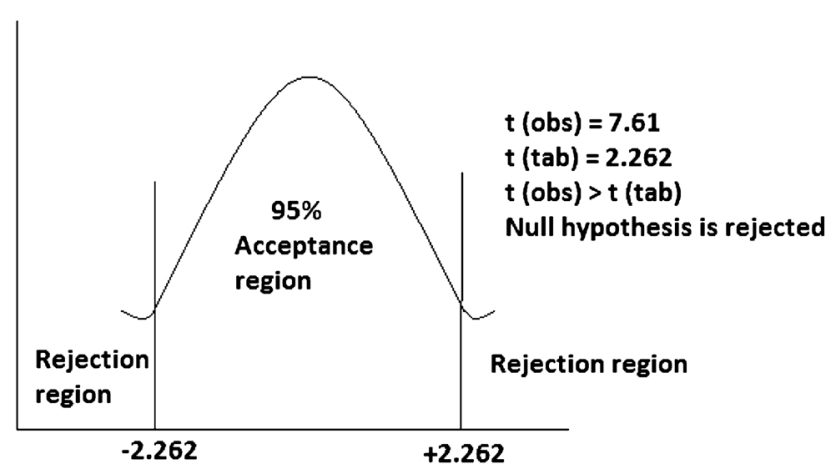

Fig. 3 Probability chart for $t$-distribution for two-tailed test

For paired $t$ test

$t_{\text {calculated }}=\left(D_{\text {avg }}-0\right) /\left(\sigma_{\text {diff }} / \sqrt{ } n\right)$,

Where $n=$ number of matched pairs, $D_{\text {avg }}=$ Mean of differences, $\sigma_{\text {diff }}=$ Standard deviation of differences.

$D_{\text {avg }}$ (mean of differences $)=\left(\sum D_{\mathrm{i}}\right) / n=29.95$

Standard deviation $\sigma_{\text {diff }}=\sqrt{ }\left[\sum\left\{D_{\mathrm{i}}-\left(D_{\text {avg }}\right)^{2} \cdot n\right\} /\right.$ $n-1]=12.446$

From Eq. 7, the calculated value of $t$ is $t_{\text {observed }}=7.61$, whereas $t_{\text {tabulated }}=2.262$ at $5 \%$ level of significance for 9 degrees of freedom (d.f.) for 2-tailed t-distribution (Kothari 2004). Since $t_{\text {calculated }}>t_{\text {observed }}$, null hypothesis that the experiment did not bring any change in the concentration of zinc ions in the solution is rejected and alternate hypothesis that the experiment in removing zinc ions from contaminated solution was succeccful accepted (Fig. 3).

\section{Hypothesis testing to infer that the higher adsorbent dose helps in higher \% removal of zinc ions}

Chi-square test was applied to the data collected from the experiments conducted for zinc ion removal from samples of initial zinc ion concentration of 10 and $100 \mathrm{mg} / \mathrm{L}$ with adsorbent dosages 1 and $10 \mathrm{~g} / \mathrm{L}$ at $\mathrm{pH}=5$ (Tables 3,4 ).
Table 3 Observed frequencies for zinc ion removal for initial zinc ion concentration of 10 and $100 \mathrm{mg} / \mathrm{L}$ and adsorbent dosages 1 and $10 \mathrm{~g} / \mathrm{L}$ at $\mathrm{pH} 5$

\begin{tabular}{llll}
\hline & \multicolumn{2}{c}{$\%$} & Total \\
\cline { 2 - 3 } & $\begin{array}{l}\text { Initial } \\
\text { concentration } \\
10 \mathrm{mg} / \mathrm{L}\end{array}$ & $\begin{array}{l}\text { Initial } \\
\text { concentration } \\
100 \mathrm{mg} / \mathrm{L}\end{array}$ & \\
\hline $\begin{array}{l}\text { Adsorbent dose } \\
1 \mathrm{~g} / \mathrm{L}\end{array}$ & 9 & 1 & $10=\mathrm{A}$ \\
$\begin{array}{l}\text { Adsorbent dose } \\
10 \mathrm{~g} / \mathrm{L}\end{array}$ & 75 & 40 & $115=\mathrm{a}$ \\
\begin{tabular}{l} 
Total \\
\hline
\end{tabular} & $84=\mathrm{B}$ & $41=\mathrm{b}$ & $125=\mathrm{N}$ \\
\hline
\end{tabular}

Table 4 Calculation for Chi square

\begin{tabular}{lccl}
\hline Groups & $O_{i j}$ & $E_{i j}$ & $\left(O_{i j}-E_{i j}\right)^{2} / E_{i j}$ \\
\hline $\mathrm{AB}$ & 9 & 6 & 1.5 \\
$\mathrm{Ab}$ & 1 & 3.28 & 1.58 \\
$\mathrm{aB}$ & 75 & 77.28 & 0.067 \\
$\mathrm{ab}$ & 40 & 37.72 & 0.14 \\
\hline
\end{tabular}

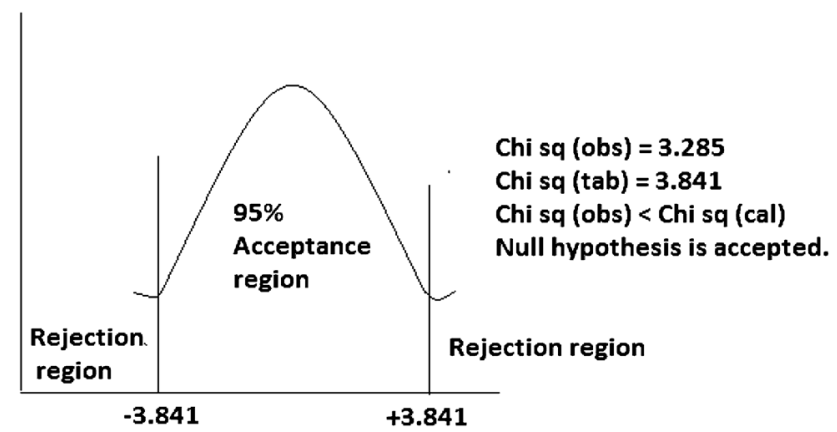

Fig. 4 Probability chart for Chi-square distribution for effectiveness of the adsorption experiment

Null hypothesis $H_{\mathrm{o}}$ : \% removal is higher with higher adsorbent dose

Alternate hypothesis $H_{\mathrm{a}}$ : \% removal decreases with adsorbent dose

If $O_{i j}=$ Observed frequencies of the cell in the $i$ th row and $j$ th column.

$E_{i j}=$ Expected frequencies of the cell in the $i$ th row and $j$ th column.

$\chi^{2}=\sum\left\{\left(O_{i j}-E_{i j}\right)^{2} / E_{i j}\right\}$,

From Eq. 8, the calculated value of $\chi^{2}$ is $\chi_{\text {observed }}^{2}=3.285$ whereas $\chi_{\text {tabulated }}^{2}=3.841$ at $5 \%$ level of significance for 1 degrees of freedom (d.f.) for $\chi^{2}$-distribution (Kothari 2004). Since $\chi_{\text {observed }}^{2}<\chi_{\text {tabulated }}^{2}$, null hypothesis that the higher adsorbent dose helps in higher \% removal of zinc ions is accepted (Fig. 4). 


\section{Adsorption isotherms}

Experimental data were analysed using Langmuir and Freundlich adsorption isotherm equations (Eqs. 2 and 3).

\section{Langmuir isotherm}

The experimental data were used to check whether the Langmuir isotherm equation was favourable or not. Metal ion concentration $c(\mathrm{ppm})$ was plotted against $c / W$, where $W$ is adsorbent loading (g adsorbed/g solid) to give isotherm curve on arithmetic graph (Table 5; Fig. 5).

From the plot, the slope of the isotherm obtained was 102.98 and the Langmuir isotherm constant $\mathrm{K}$ obtained was 0.008582 . The value of $K(<1)$, indicated a linear type and hence a favourable isotherm. Value of Karl pearson's correlation coefficient was obtained as 0.998225 (Eq. 1), indicating a high degree of correlation between two variables.

Table 5 Experimental data for Langmuir isotherm

\begin{tabular}{llll}
\hline C, ppm & $\begin{array}{l}\text { Adsorbent } \\
\text { dose, } \mathrm{mg}\end{array}$ & $\begin{array}{l}\text { Quantity of zinc } \\
\text { adsorbed, mg }\end{array}$ & $\begin{array}{l}W=\mathrm{mg} \text { adsorbed } / \mathrm{mg} \\
\text { adsorbent }\end{array}$ \\
\hline 10 & 10,000 & 7.5 & 0.00075 \\
20 & 10,000 & 15 & 0.015 \\
30 & 10,000 & 21 & 0.0021 \\
40 & 10,000 & 26 & 0.0026 \\
50 & 10,000 & 30 & 0.003 \\
60 & 10,000 & 34 & 0.0034 \\
70 & 10,000 & 38 & 0.0038 \\
80 & 10,000 & 41 & 0.0041 \\
90 & 10,000 & 43 & 0.0043 \\
100 & 10,000 & 44 & 0.0044 \\
\hline
\end{tabular}

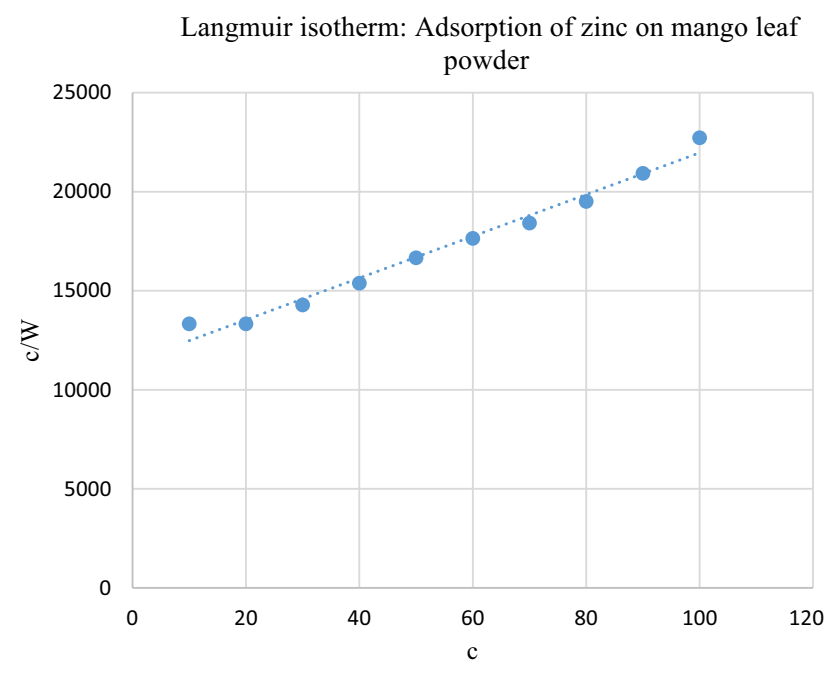

Fig. 5 Langmuir Isotherm plot
Table 6 Experimental data for Freundlich isotherm

\begin{tabular}{llll}
\hline$C, \mathrm{mg} / \mathrm{L}$ & $W=\mathrm{mg}$ adsorbed/mg adsorbent & $\log c$ & $\log W$ \\
\hline 10 & 0.00075 & 1 & -3.12 \\
20 & 0.015 & 1.30 & -2.82 \\
30 & 0.0021 & 1.48 & -2.68 \\
40 & 0.0026 & 1.60 & -2.59 \\
50 & 0.003 & 1.70 & -2.52 \\
60 & 0.0034 & 1.78 & -2.49 \\
70 & 0.0038 & 1.85 & -2.42 \\
80 & 0.0041 & 1.90 & -2.38 \\
90 & 0.0043 & 1.95 & -2.37 \\
100 & 0.0044 & 2 & -2.36 \\
\hline
\end{tabular}

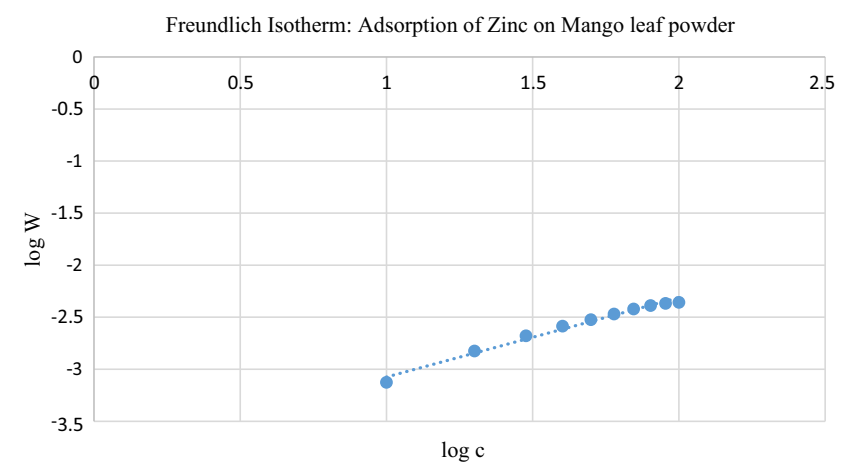

Fig. 6 Freundlich isotherm plot

Freundlich isotherm

Favourabilty of Freundlich adsorption isotherm was checked using Freundlich isotherm equation. Logarithmic values of $c$ (metal ion concentration, $\mathrm{ppm}$ ) were plotted against logarithmic values of $W$ (adsorbent loading, g adsorbed/g solid) to obtain isotherm curve (Table 6; Fig. 6).

Value of slope obtained from plot was 0.725331 . Since slope $m<1$, Freundlich adsorption isotherm was found to be a favourable fit for the adsorption data. Value of Karl pearson's correlation coefficient was 0.95311 , indicating a high degree of correlation between two variables.

\section{Conclusions}

Hypotheses are statements or assumptions made clearly and concisely for the data obtained from experiments which need testing, i.e. to accept or reject them. Hypothesis testing is a technique to validate these assumptions. In the present study, we made assumptions, which were expressed as the null hypothesis, for different situations (a) to judge the optimum value of $\mathrm{pH}$ for maximum removal of $\mathrm{Zn}$ ions by mango tree leaves (b) to judge 
the success of the experiment (c) to infer that the higher adsorbent dose helped in higher \% removal of zinc ions. The problems were tested using $t$ test, paired $t$ test and Chisquare test within $5 \%$ level of confidence. Results showed that our calculated values fall inside the acceptance region of the probability charts.

Further, experiment data were analysed through Langmuir and Freundlich adsorption isotherms. Results showed the linear fit of data into the isotherm equations and hence the favourable isotherms. Values of Karl Pearson's correlation coefficients obtained were 0.99 and 0.95 for Langmuir and Freundlich adsorption isotherms respectively, which show higher degree of correlation between the two variables.

$F$ test and analysis of variance (ANOVA) to test the differences of means between multiple samples at the same time are recommended for future studies.

Open Access This article is distributed under the terms of the Creative Commons Attribution 4.0 International License (http:// creativecommons.org/licenses/by/4.0/), which permits unrestricted use, distribution, and reproduction in any medium, provided you give appropriate credit to the original author(s) and the source, provide a link to the Creative Commons license, and indicate if changes were made.

\section{References}

Anderson TW (1958) An introduction to multivariate analysis. Wiley, New York

Bowley AL (1937) Elements of Statistics, 6th edn. P.S.King and Staples Ltd., London

Cafer S, Omer S, Ahin MM (2012) Applications on agricultural and forest waste adsorbents for the removal of lead (II) from contaminated waters. Int J Environ Sci Technol 9:379-394

Chance WA (1975) Statistical methods for decision making. D.B. Taraporevala Sons \& co. Pvt Ltd., Bombay

Conrad K, Hansen HCB (2007) Sorption of zinc and lead on coir. Bioresour Technol 98:89-97
Dabrowski A (2001) Adsorption-from theory to practice. Adv Colloid Interface Sci 93:135-224

Ferhan C, Ozgur A (2011) Activated carbon for water and wastewater treatment: integration of adsorption and biological treatment, 1st edn. WILEY-VCH Verlag GmbH and Co, KGaA, Weinheim

Goel PK (2006) Water pollution, causes, effects and control, Revised second edition. New age international publishers, New Delhi

Kaushal A, Singh SK (2016a) Application of statistical tools and hypothesis testing of adsorption data obtained for removal of heavy metals from aqueous solutions. Int $\mathrm{J}$ Adv Res Innov 4:82-84

Kaushal A, Singh SK (2016b) Removal of Zn (II) from aqueous solutions using agro-based adsorbents. Imp J Interdiscip Res 2(6): $1215-1218$

Kothari CR (1984) Quantitative techniques, 2nd edn. Vikas Publishing House Pvt. Limited, New Delhi

Kothari CR (2004) Research methodology: methods and techniques. 2nd revised edn. New Age International Publishers, New Delhi

McCabe WL, Smith JC, Harriott P (1993) Unit operations of chemical engineering, International edn. McGraw-Hill Book Co., Singapore

Raval NP, Shah PU, Shah NK (2016) Adsorptive removal of nickel (II) ions from aqueous environment: a review. J Environ Manag 179:1-20

Shah PU, Raval NP, Shah NK (2015) Adsorption of copper from an aqueous solution by chemically modified cassava starch. J Mater Environ Sci. 6:2573-2582

Shah PU, Raval NP, Shah NK (2016) Cadmium (II) removal from an aqueouys solution using CSCMQ grafted coplolymer. Desalination Water Treat. doi:10.1080/19443994.2016.1178179

Sharma N, Tiwari DP, Singh SK (2014) The efficiency appraisal for removal of malachite green by potato peel and neem bark: isotherm and kinetic studies. Int J Environ Eng 5:83-88

Singh SK, Narwal N (2015) Assessment of fixed bed column reactor using low cost adsorbent (rice husk) for removal of total dissolved solids. Int J Adv Res Innov 3:405-410

Tiwari DP, Singh SK, Sharma N (2014) Sorption of methylene blue on treated agricultural adsorbents. Water Sci, App. doi:10.1007/ S13201-014-0171-0

Treybal RE (1981) Mass transfer operations International Edition, 3rd edn. McGraw Hill Book Co., Singapore

Wong KK, Lee CK, Low KS, Haron MJ (2003) Removal of $\mathrm{Cu}$ and $\mathrm{Pb}$ by tartaric acid modified rice husk from aqueous solutions. Chemosphere 50:23-28 